\title{
Therapeutic application of linked color imaging for colorectal endoscopic mucosal resection
}
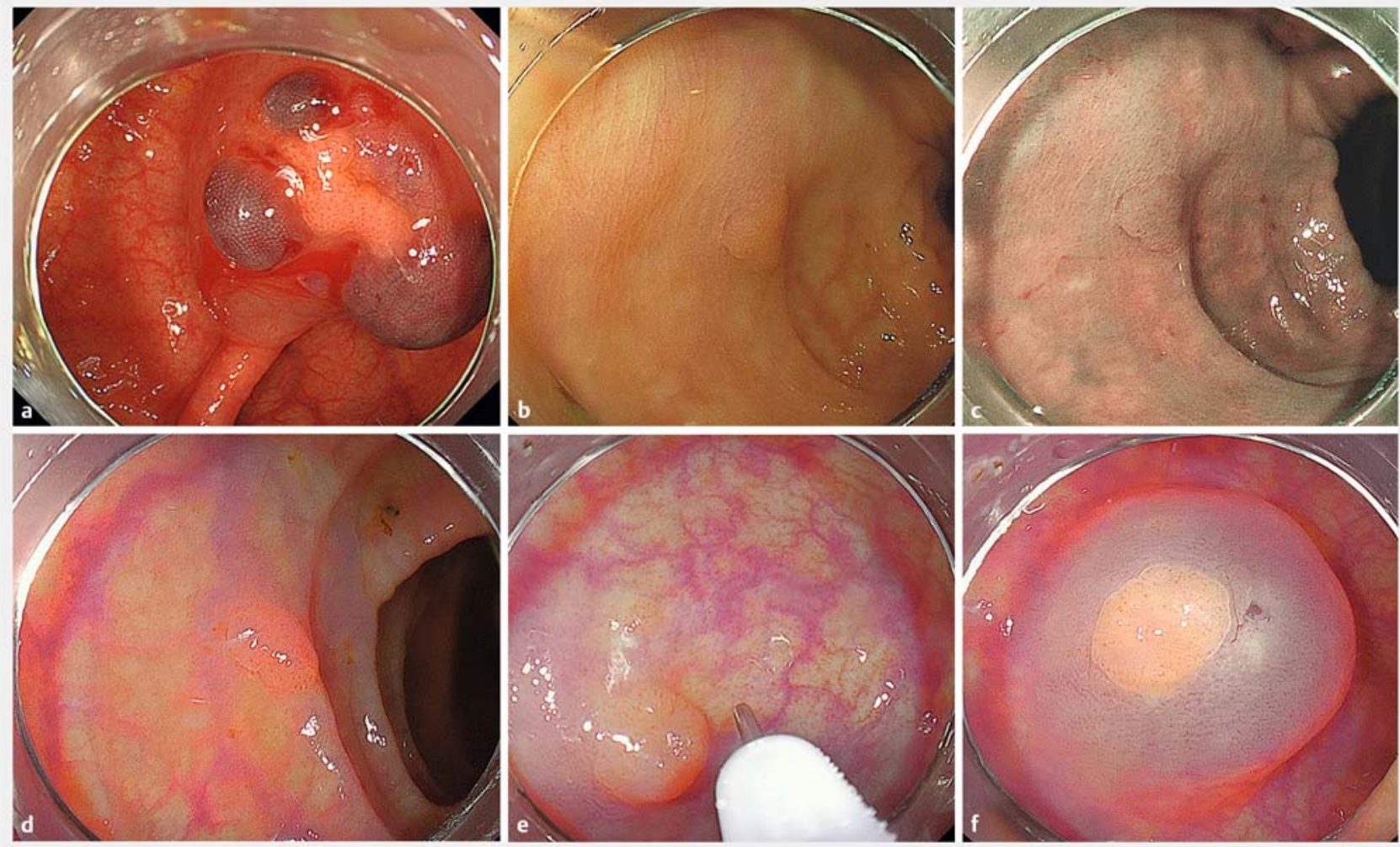

- Fig. 1 Endoscopic images illustrating the advantages of linked color imaging (LCI) during endoscopic mucosal resection. a Improper injection can induce hematoma formation. b Superficial vessels around a colorectal polyp are invisible with white-light imaging. c Superficial vessels are also unclear with bright-light imaging. $\mathbf{d} \mathrm{LCl}$ shows the orientation of vessels around the polyp. $\mathbf{e}$ The injection needle pinpoints a site lacking vessels. $\mathrm{f}$ Unnecessary hematoma formation and bleeding can be avoided during mucosal injection.

Linked color imaging (LCl; Fujifilm Co., Tokyo, Japan) is a newly developed image-enhanced technique that has shown high diagnostic performance in the field of gastrointestinal endoscopy. LCl enhances color separation of the mucosal layer, making red regions redder and white regions whiter. This contributes to the detection of gastric cancer [1], ulcerative colitis [2], colorectal polyps [3,4], and other lesions. Although the diagnostic productivity is steadfast, the treatment benefit of $\mathrm{LCl}$ remains unclear or limited [5]. We herein introduce an advantage of $\mathrm{LCl}$ with respect to increasing the safety of endoscopic mucosal resection (EMR), illustrating the efficacy of $\mathrm{LCl}$ in the treatment field.

Compared with white-light imaging, narrow-band imaging, and bright-light imaging, the view of the blood vessels in the superficial layer is much more conspicuous when obtained by $\mathrm{LCl}$. When performing EMR, local injection is the first crucial step and the basis of later procedures such as polyp removal by snaring. However, injury to the superficial vessels invisible with white light sometimes induces hematoma formation, making subsequent snaring difficult ( Fig.1a). LCl can more precisely reveal the running of the superficial ves- sels around a colorectal polyp than can white light imaging ( Fig.1 b) and bright-light imaging ( $\mathbf{F i g} \cdot \mathbf{1} \mathbf{c}$ ). LCl enhances the reddish, glaring characteristics of the vessels, pinpointing safe sites for needling ( $\triangleright$ Fig.1d). Consequently, the clinician can avoid needling blood

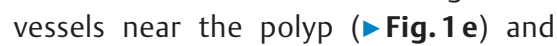
prevent unnecessary bleeding and hematoma formation ( $>$ Fig. 1 f), leading to secure completion of EMR.

White-light imaging, bright-light imaging, and $\mathrm{LCl}$ for EMR local injections are compared in Video 1 . Only $\mathrm{LCl}$ shows the reddish network pattern of the superficial blood vessels. This leads 


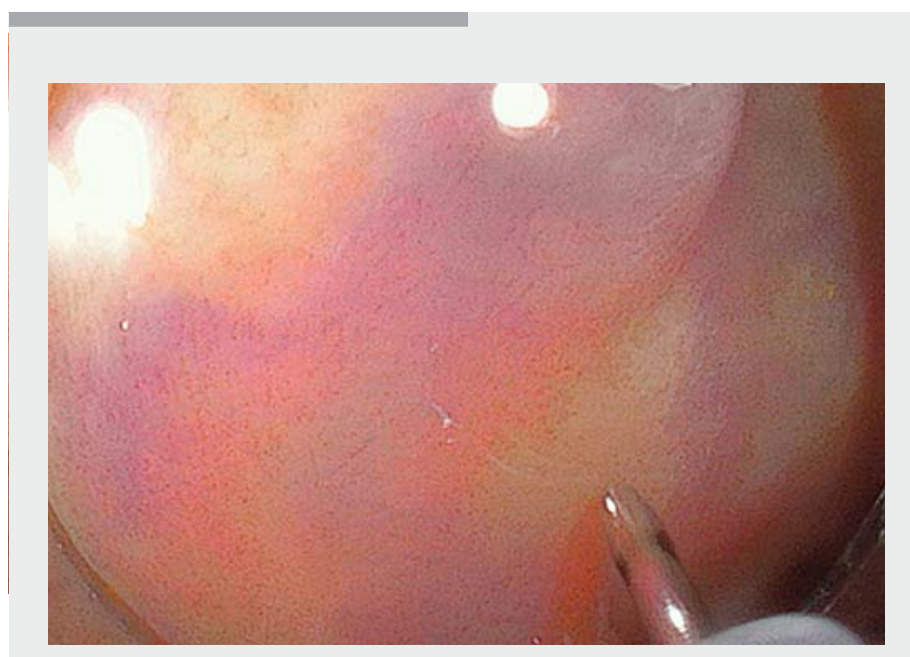

$\checkmark$ Video 1 White-light imaging only ambiguously shows the blood vessel routes, whereas linked color imaging ( $\mathrm{LCl}$ ) indicates the vessels clearly as a vivid reddish color. From injection to snaring, $\mathrm{LCl}$ allows the clinician to avoid unnecessary bleeding.
[3] Yoshida N, Naito Y, Murakami T et al. Linked color imaging improves the visibility of colorectal polyps: a video study. Endosc Int Open 2017; 6: E518-E525

[4] Min M, Deng P, Zhang W et al. Comparison of linked color imaging and white-light colonoscopy for detection of colorectal polyps: a multicenter, randomized, crossover trial. Gastrointest Endosc 2017; 86: 724 - 730

[5] Sun XT, Min M, Bi YL et al. Endoscopic submucosal dissection of a rectal neuroendocrine tumor using linked color imaging technique. Chin Med J (Engl) 2017; 9: 1127 1128

\section{Bibliography}

DOI https://doi.org/10.1055/s-0043-119984

Published online: 17.10 .2017

Endoscopy 2018; 50: E8-E9

(c) Georg Thieme Verlag KG

Stuttgart · New York

ISSN 0013-726X

\section{ENDOSCOPY E-VIDEOS}

Hideki Kobara, MD, PhD

Department of Gastroenterology and Neurology, Faculty of Medicine, Kagawa University, 1750-1 Ikenobe, Miki, Kita,

Kagawa 761-0793, Japan

Fax: +81-87-8912158

kobara@med.kagawa-u.ac.jp

None

\section{The authors}

Yasuhiro Goda, Hirohito Mori, Hideki Kobara, Noriko Nishiyama, Nobuya Kobayashi, Tatsuo Yachida, Tsutomu Masaki

Department of Gastroenterology and Neurology, Faculty of Medicine, Kagawa University, Kagawa, Japan

\section{References}

[1] Ono S, Abiko S, Kato M. Linked color imaging enhances gastric cancer in gastric intestinal metaplasia. Dig Endosc 2017; 29: 230-231

[2] Uchiyama K, Takagi T, Kashiwagi S et al. Assessment of endoscopic mucosal healing of ulcerative colitis using linked colour imaging, a novel endoscopic enhancement system. J Crohns Colitis 2017; 11: 963 - 969 https://eref.thieme.de/e-videos

Endoscopy E-Videos is a free access online section, reporting 自䍩: on interesting cases and new techniques in gastroenterological endoscopy. All papers include a high quality video and all contributions are freely accessible online.

This section has its own submission website at https://mc.manuscriptcentral.com/e-videos 